\title{
Post ERCP Migration of Biliary Stent Through Common Bile Duct Wall - A Case Report
}

\author{
Ramesh Agarwalla ${ }^{1}$, Partha Sarathi Nayak ${ }^{2}$, Snigdhendu Chand ${ }^{3}$, Gouranga Charan Nayak ${ }^{4}$, Soumen Pal ${ }^{5}$ \\ ${ }^{1}$ Director, Department of GI and Minimal Access Surgery, Fortis Hospital, Anandapur, E.M. Bypass Road, Kolkata, West Bengal \\ 700107, 2,3Senior Resident, Department of GI and Minimal Access Surgery, Fortis Hospital, Anandapur, E.M. Bypass Road, \\ Kolkata, West Bengal 700107, 4,5Senior Registrar, Department of General Surgery, Fortis Hospital, Anandapur, E.M. Bypass \\ Road, Kolkata, West Bengal 700107, India
}

Corresponding author: Dr. Ramesh Agarwalla, Director, Department of GI and Minimal Access Surgery, Fortis Hospital, Anandapur, E.M. Bypass Road, Kolkata, West Bengal 700107, India

DOI: http://dx.doi.org/10.21276/ijcmsr.2020.5.1.51

How to cite this article: Ramesh Agarwalla, Partha Sarathi Nayak, Snigdhendu Chand, Gouranga Charan Nayank, Soumen Pal. Post ERCP migration of biliary stent through common bile duct wall - a case report. International Journal of Contemporary Medicine Surgery and Radiology. 2020;5(1):A237-A238.

\section{A B S T R A C T}

Introduction: Endoscopic retrograde cholangiopancreatography (ERCP) is usually used in treatment of common bile duct (CBD) stones with or without stent insertion. Adverse events related to ERCP and stenting has been found in approximately $5 \%-10 \%$ of cases.

Case report: Here by we present a very rare case of ERCP stent migration through lateral CBD wall. Abdominal drain was removed on POD-2 and patient was discharged from hospital on POD-2. Her post-operative recovery remained uneventful.

Keywords: ERCP, CBD stones, Biliary stent, Migration

\section{INTRODUCTION}

Endoscopic retrograde cholangiopancreatography (ERCP) is usually used in treatment of common bile duct (CBD) stones with or without stent insertion which is followed by laparoscopic cholecystectomy (LC) for gall bladder (GB) stones. ${ }^{1}$ The ERCP and stenting presents early complications such as haemorrhage, pancreatitis, cholangitis, and perforation, andlate complications such as stent migration and late perforation. ${ }^{2}$ Post ERCP stent migration is a rare complication but can lead to serious complications and produce significant morbidity and mortality. ${ }^{3}$

\section{CASE REPORT}

A 41 year old female with diabetes mellitus and hypertension as comorbidities presented to our outpatient department for LC following ERCP and stenting for CBD stones. Patient had undergone ERCP with papillotomy and insertion of $7 \mathrm{fr}$ pigtail catheter 5 weeks back. On admission her liver function tests were within normal limits and her ultrasonography whole abdomen showed contracted GB with mild sludge inside, CBD was normal in diameter with stent in situ. Intraoperatively it was found that the $\mathrm{CBD}$ stent was outpouching from lateral wall of CBD as shown in figure (12). $\mathrm{CBD}$ stent was removed by incising the outpouching on lateral CBD wall (fig. 3). Rent formed by stent was checked for bile leak and then closed with clips (fig. 4-6). LC was done. A 24 fr abdominal drain was placed in Morrison's pouch for observation for any bile leak. Nasogastric tube was kept in place which was removed on post-operative day
1(POD-1). Abdominal drain was removed on POD-2 and patient was discharged from hospital on POD-2. Her postoperative recovery remained uneventful.

\section{DISCUSSION}

In 1980 Soehendra et $\mathrm{al}^{4}$ introduced transpapillary biliary drainage using plastic biliary stent. Since then biliary stents are often used for the treatment of benign obstructive biliary disease. Biliary stents nevertheless causes serious complications and one of these is stent migration which occurs in up to $10 \%$ of patients. ${ }^{5}$ Migration of endoscopically placed biliary stents is a well-recognized complication of endoscopic retrograde cholangiopancreatography. Post ERCP distal migration of a biliary stent are rare complications with incidence less than $6 \%$. $^{2,6}$

Biliary stents however are not without complications. The complication rate ranges between $8 \%$ and $10 \%$, with a mortality rate below $1 \%$. Complications specific to the stents include migration, occlusion, and intestinal perforation., ${ }^{2,7}$ Numerous stent-related adverse events have been described, including stent occlusion, bowel wall perforation, and injury to the biliary or pancreatic duct. Unintended migration of plastic biliary or pancreatic stents has been reported in $5 \%$ to $6 \%$ of patients. ${ }^{2}$ If the stent migrates to the digestive tube, then $43 \%$ are evacuated spontaneously. Plastic stent migration is more frequent in patients with benign pathology without severe stenosis of the bile duct or papilla. ${ }^{2}$

The migration of biliary stents may be due to type and nature of stents used or the duration between ERCP and LC when the stent in situ. Most cases of distal biliary stent 


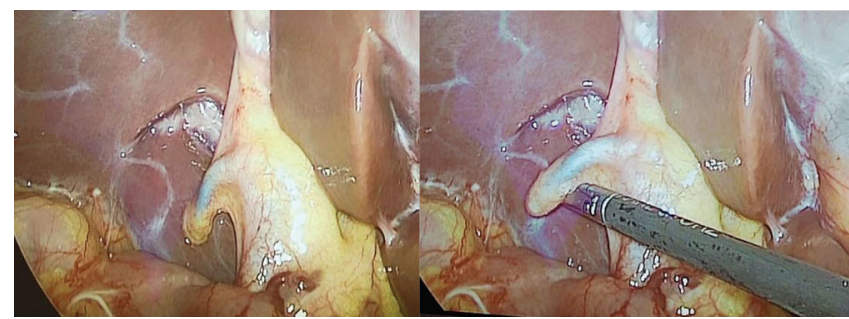

Figure-1: Proximal migration of stent to lateral CBD wall Figure-2: Stent with Rent in CBD wall lifted with Maryland forceps

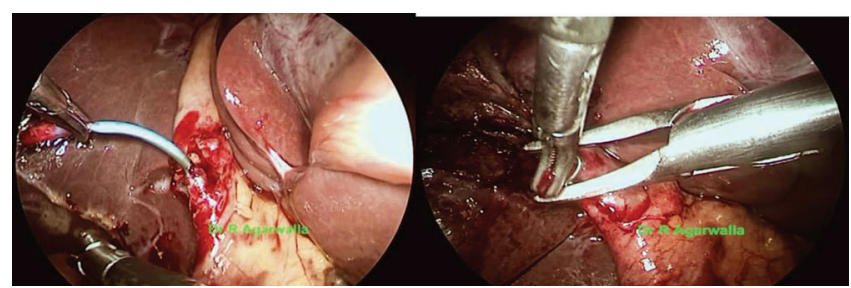

Figure-3: Stent removed after making an Incision over rent Figure-4: Clips being applied over rent in CBD wall

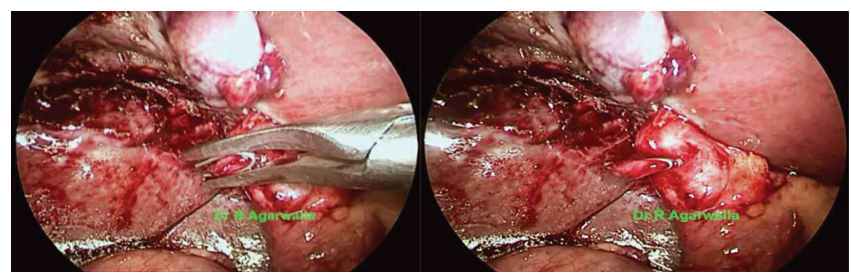

Figure-5: Rent with opening in CBD wall closed with clips Figure-6: Rent closed and gall bladder dissected

migration are due to malignant strictures, larger diameter stents, and shorter stents. ${ }^{5}$ Sphincter of Oddi dysfunction and longer stents were associated with proximal pancreatic stent migration. Migration of stents out of the common bile duct occurred more frequently in papillary stenosis. ${ }^{2}$

This stent migration may sometimes lead to CBD injury followed by formation of CBD stricture or perforation of CBD leading to biliary peritonitis. Treatment for stent retrieval is carried out endoscopically ${ }^{8}$, using baskets, forceps or the lasso technique ${ }^{9,10}$, except for stents that have perforated the wall or protrude through a duodenal diverticulum.

\section{CONCLUSION}

Post ERCP bile duct stent migration to lateral CBD wall is a rare complication. There are no such reported cases previously. This case confirms about careful placement of stent, type of stent to be used and duration of stent to remain inside CBD and proper follow up so that we can avoid serious complications. Stent migration is an important complication. Multiple risk factors were associated with stent migration and need to be considered in the development of new stent types.

\section{REFERENCES}

1. Kahaleh M, Freeman M. Prevention and management of post-endoscopic retrograde cholangiopancreatography complications. Clin Endosc. 2012; 45(1):305-312.
2. Johanson JF, Schmalz MJ, Geenen JE. Incidence and risk factors for biliary and pancreatic stent migration. Gastrointest Endosc 1992; 38(3):341-346.

3. Namdar T, Raffel AM, Topp SA, et al. Complications and treatment of migrated biliary endoprostheses: a review of the literature. World J Gastroenterol 2007;13(40):5397-5399.

4. Blake AM, Monga N, Dunn EM. Biliary stent causing colovaginal fistula: case report. JSLS. 2004;8(1):73-5.

5. Mueller PR, Ferrucci JT, Teplick SK, vanSonnenberg E, Haskin PH, Butch RJ, et al. Biliary stent endoprosthesis: analysis of complications in 113 patients. Radiology 1985; 156(3):637-639.

6. Tarnasky PR, Cotton PB, Baillie J, et al. Proximal migration of biliary stents: Attempted endoscopic retrieval in forty-one patients. Gastrointest Endosc. 1995; 42(2):513-520.

7. Chaurasia OP, Rauws EA, Fockens P, Huibregtse K. Endoscopic techniques for retrieval of proximally migrated biliary stents: the Amsterdam experience. Gastrointest Endosc 1999; 50(4): 780-785.

8. Arhan M, Odemiş B, Parlak E, Ertuğrul I, Başar O. Migration of biliary plastic stents: experience of a tertiary center. Surg Endosc 2009; 23(6): 769-775.

9. Diller R, Senninger N, Kautz G, et al. Stent migration necessitating surgical intervention. Surg Endosc. 2003; 17(1):1803.

10. Morgener K, Baillie J. Retrieval of distally migrated impacted biliary endoprosthesis using a novel guide wire basket "lasso" technique. Gastrointest Endosc. 1999; 50(6):93-4.

\section{Source of Support: Nil; Conflict of Interest: None}

Submitted: 14-01-2020; Accepted: 16-02-2020; Published online: 20-03-2020 